\title{
Bases teórico-políticas del bloque ibérico: La relación peninsular en la fase de inflexión de la II Guerra Mundial, 1942-1945
}

\author{
Juan Carlos Jimenez Redondo
}

\section{CONDICIONANTES HISTÓRICOS DE LA RELACIÓN PENINSULAR}

Al abordar las relaciones entre España y Portugal cualquiera que sea el momento histórico escogido, resulta siempre sorprendente comprobar cómo una frontera política, ausente de impedimentos naturales, ha podido levantar un muro difícilmente franqueable entre ambas comunidades. De hecho, la noción de vecindad tiene en el caso hispano-portugués una dimensión estática, basada en el hecho de una contigüedad geográfica, que contrasta con la dimensión dinámica propia de una relación de vecindad, donde los actores no sólo están unidos geográficamente sino que se da una comunicación y relación efectiva entre ellos?

Esta situación de ignorancia e incomprensión mutua tiene su asiento en consideraciones de carácter histórico que han ido configurando una serie de permanencias, de nociones socializadas que constituyen el substrato colectivo que dota de sentido a esa percepción ${ }^{2}$. En consecuencia, es imprescindible abordar el contencioso peninsular partiendo de una previa revisión de datos históricos, ya que la historia no sólo proporciona unos puntos de comparación en el tiempo, sino que permite seguir las líneas evolutivas del problema objeto de estudio y la identificación de los factores que desempeñan una función dominante ${ }^{3}$.

\footnotetext{
1 ARENAL, Celestino del: "En torno a la noción de vecindad en las relaciones internacionales", en AREnal, Celestino del (Coord.): Las relaciones de vecindad. Bilbao, Universidad del País Vasco, 1987. pp. 19-27.

2 JOVER, José $\mathrm{M}^{\mathrm{a}}$ : “La percepción española de los conflictos europeos", en Revista de Occidente, $n^{\circ} 57,(1986)$, pp. 5-42.

3 Merle, Marcel: Sociologia de las relaciones internacionales. Madrid, Alianza, 1986. pp. 66-67.
} 
Desde que en 1640 los portugueses rechazaron violentamente su inclusión en una España unitaria, el iberismo, entendido como el deseo permanente de reunificación de ambas naciones bajo un estado común peninsular ${ }^{4}$, ha sido el verdadero factor condicionante de las relaciones entre España y Portugal, alimentando las dos opciones políticas divergentes que desde entonces se hicieron permanentes. Por parte española, recomponer la unidad perdida, cuya imposibilidad motivará una omisión e infravaloración permanente de la nación vecina; por parte lusa, preservar su integridad nacional por medio de una política de "costas viradas" hacia España y de expansión ultramarina, que con el apoyo de la principal potencia marítima, le permitiera aliviar la presión centrípeta española y edificar las bases de su proyecto nacional ${ }^{5}$.

Contencioso iberista identificado como sinónimo de peligro español, raíz de esa historia de antagonismo secular ${ }^{6}$, que con algunos momentos de inflexión ${ }^{7}$ llega, con todo su potencial disgregador, hasta el mismo inicio de la Guerra Civil Española. La convergencia de dos regímenes opuestos como eran la dictadura salazarista y la II República española hipertrofió esa percepción, al asociarse la amenaza iberista, de una República en busca del ideal de una Iberia solidaria de pueblos en libertad ${ }^{8}$, con el peligro desestabilizador de un régimen republicano potencialmente revolucionario, donde los exilados lusos encontraban no sólo refugio y protección, sino también importante ayuda para sus actividades ${ }^{9}$. Esto hizo que

4 Serrao, Joel: Dicionário de história de Portugal, 4 vols. Lisboa, Iniciativas editoriais, 1968. vol. II. pp. 461-463.

MACEDO, Jorge Borges de: Constant of the History of Portugal. Lisboa, Academia das Ciencias, 1981.

6 Antagonismo que sólo se intentó superar a través de soluciones de convergencia en las décadas centrales del siglo XIX. Mascarenhas, Manuela: A questao ibérica, 1850-1870. Braga, Separata da Revista Brácara Augusta, 1980. LOPEz-CORDÓN, Ma Victoria: El pensamiento político internacional del federalismo español (1868-1874). Barcelona, Planeta, 1975. Nido y SEgalverva, Juan del: La unión iberica. Estudio critico, histórico de este problema. Madrid, Tipografía de Prudencio P. de Velasco, 1919. Rocamora, J.A.: El nacionalismo ibérico. Valladolid, Universidad. 1994.

Coincidentes, uno, con la crisis del “ultimatum» portugués y, otro, durante la Dictadura de Primo de Rivera, al alejarse del binomio indiferencia-ímpetu iberista. La perspectiva más lúcida y esclarecedora a este respecto la aporta Hipólito de la Torre en sus obras Antagonismo y fractura peninsular. Madrid, Espasa-Calpe, 1983 y Del "peligro español» a la amistad peninsular. Madrid, UNED, 1984. También VAzQUEZ, Pilar: A Espanha ante o "Ultimatum". Lisboa, Horizonte, 1975.

${ }_{8}$ EGido, Ma A.: La concepción de la política exterior española durante la /l República, 19311936. Madrid. UNED, 1987.

9 Percepción evidente en la recopilación documental DIEZ AÑOS DE POLITICA EXTERNA PORTUGUESA (1936-1948). A naçao portuguesa e a Segunda Guerra Mundial. 12 vols. Lisboa, Imprenta Nacional, 1964-1993. vol. III. (1964). p. 49 
los dirigentes del Estado Novo consideraran seriamente amenazada no sólo su estabilidad, sino incluso la integridad nacional del país ${ }^{10}$, en una percepción claramente exagerada de forma consciente e interesada. Por eso, cuando las elecciones de febrero de 1936 dieron el gobierno al Frente Popular, la percepción portuguesa de que España quedaba envuelta en un irreversible proceso revolucionario se tornó definitiva. Se descartaba la posibilidad de entendimiento, en fase de concreción durante el bienio radical-cedista al ser gobiernos sin veleidades iberistas ni, por supuesto, revolucionarias, y se decidió luchar contra la República apostando a favor de quienes trabajaban para derrumbarla ${ }^{11}$.

\section{LA PERVIVENCIA IBERISTA: ESPAÑA Y PORTUGAL EN EL MARCO DE LOS CONFLICTOS BELICOS. DE LA GUERRA CIVIL ESPAÑOLA A LA CONFLAGRACIÓN MUNDIAL}

La sublevación militar de julio de 1936 permitió al gobierno salazarista poner en marcha una política, consciente y autónoma, con la que afrontar activamente los peligros percibidos de la República. Iniciativa traducida en un apoyo incondicional e inquebrantable a los militares sublevados ${ }^{12}$ expresado, sobre todo, en su decisivo apoyo diplomático. Es decir, en el uso de medios políticos para alcanzar el objetivo de la unidad peninsular en orden de primacia a cualquier otra posible forma de actuación ${ }^{13}$.

La prioridad concedida a la problemática española supuso un significativo punto de inflexión en la política exterior lusa, anclada tradicionalmente en una dialéctica de oposición Europa/Ultramar ${ }^{14}$. Resuelta secularmente en favor de una proyección marítima amparada bajo la protección británica, el encadenamiento de los conflictos bélicos alteró esta constante, por lo menos de forma momentánea, aunque no variase la decidida vocación atlantista del salazarismo. En cualquier caso, existe

10 Es bien significativa en este sentido la obra de Hipólito de la Torre. La relación peninsular en la antecamara de la Guerra Civil española. Mérida. UNED, (1988). También OLIVEIRA, César: Portugal y la /l República española. Madrid, ICl, 1986.

11 LOFF, Manuel: El papel de Pedro Teotónio Pereira en la definición de la politica exterior portuguesa, 1937-1940 (Trabajo no publicado, gentileza del autor).

12 Olivielra, César: Salazar e a Guerra Civil de Espanha. Lisboa, O Jornal, 1988.

13 Delgado, Iva: Portugal e a Guerra Civil de Espnaha. Lisboa, Europa-América, 1980, p. 38

14 Magalhaes, José Calvet de: "Portugal e a integraçao europeia" en Estrategia, $n^{\circ} 4$ (1987), pp. 33-74. 
una significativa modificación impuesta por la realidad de la coyuntura internacional que, a pesar de los intentos de equilibrio llevados a cabo, no hará sino revelarse cada vez con mayor fuerza en momentos posteriores, introduciendo un factor de profunda contradicción entre la ubicación del pais dentro de la problemática de ruptura y reconstrucción europea propiciada por la guerra y el radical rechazo ideológico-dogmático del salazarismo a aceptar esta continentalidad, privilegiando no sólo en su discurso sino también en su acción, su decidida vocación imperial.

Esta inflexión conllevó también una política menos dependiente de las directrices británicas, dotando al pais de mayor autonomia y capacidad de iniciativa en la escena internacional. Pero nunca hasta el extremo de provocar un enfrentamiento irreversible, dado el especial significado de la Alianza como base estructural del proceso de desarrollo del capitalismo portugués ${ }^{15}$. Por ello, la ruptura no se consumó, normalizándose la relación, aunque ya sobre nuevas bases ${ }^{16}$, debido a la convergencia de intereses estratégicos impuesta por el difícil contexto internacional ${ }^{17}$. Coincidencia estratégica encaminada a conseguir la neutralización de la península en caso de guerra en Europa, a través de una política de armonización ibérica, que se vió favorecida por las iniciativas del gobierno de Burgos encaminadas a la conclusión de un tratado que le permitiera finalizar la guerra civil sin el riesgo de una posible presencia británica en la frontera oeste, en caso de un conflicto europeo generalizado ${ }^{18}$.

El Tratado de Amistad y No Agresión de 17 de marzo de 1939 nacía fruto de los deseos expresados por ambos Estados de encarar la guerra desde una posición de neutralización y marginación de la península como escenario bélico, aunque en las negociaciones se dejaba traslucir ya, por parte del gobierno franquista, el intento de buscar la primacía de la alianza

\footnotetext{
Rosas, Fernando: O Salazarismo e a Aliança Luso-Británica. Lisboa, Fragmentos, 1988, p. 7. Ibidem, p. 24

Rosas, Fernando: “A neutralidade portuguesa durante a II Guerra Mundial no quadro da
} política externa do Estado Novo", en TORRE, Hipólito de la (Coord.): Portugal, España y Europa. Cien años de desafío. Mérida, UNED, 1991, pp. 117-129. ToRAE, Hipólito de la: «Portugal, el mar y la alianza inglesa", en Torre, Hipólito de la (Coord.): España, Portugal y la OTAN. Mérida, UNED, 1989, pp. 29-47

18 HALSTEAD, Charles: "Peninsular Purpose: Portugal and its 1939 Treaty of Friendship and Non Agression with Spain", en II Politico, n² 2, (1980), pp. 287-311. DEZ AÑOS... vol. V (1967), pp. 444-447. ARCHIVO GENERAL DE LA ADMINISTRACION (AGA). Caja 6631. Nicolás Franco a Conde de Jordana. Lisboa, 20 de septiembre de 1938. NogUEIRA, Franco: Salazar III: As grandes crises (1936-1945). Porto, Livraria Civilizaçao, 1983, p. 175. COMISSAO DO LIVRO NEGRO SOBRE O REGIME FASCISTA (CLNSRF): Correspondencia de Pedro Teotonio Pereira para Oliveira Salazar, 4 vols (1931-39; 1940-41; 1942; 1943-44). Lisboa, 1987-1991. Vol. I, p. 133. 
peninsular sobre la británica ${ }^{19}$, objetivo esencial que se irá perfilando posteriormente de forma más nítida. Pretensión sin seguimiento en el país vecino, pues para el gobierno luso el Tratado no significaba una alteración importante ni en las relaciones existentes con Gran Bretaña, ni modificaba las obligaciones y derechos resultantes de la Alianza Luso-británica ${ }^{20}$. El Tratado aparecía, así, como una garantía jurídica que vinculaba al enemigo tradicional en el sentido de respetar la inviolabilidad de las fronteras, to que indirectamente podria significar la renuncia española a una política ibérica agresiva.

La decidida actuación del gobierno portugués en favor del bando franquista durante la Guerra Civil, tuvo otra consecuencia fundamental: que éste quedó enganchado en una línea de apoyo al Nuevo Estado Español de la cual le sería enormemente difícil despegarse ${ }^{21}$. Sin duda, para Salazar el desenlace de la Guerra Civil fue el más favorable y deseado ${ }^{22}$, pero no resolvió uno de sus aspectos esenciales: las veleidades iberistas provenientes del otro lado de la frontera. El iberismo no era patrimonio exclusivo de los republicanos sino que también estaba presente en las nuevas fuerzas triunfantes, principal y casi exclusivamente en el pensamiento falangista ${ }^{23}$, que iba en estos momentos acentuando su carácter orientador de las directrices teóricas de la política exterior española. Sin embargo, el apoyo ofrecido por el pais vecino a la causa franquista hizo atemperar los postulados anexionistas más radicales en beneficio de un difuso pseudoiberismo de claras connotaciones paternalistas ${ }^{24}$. Actitud equivoca

19 Además, se dejaba claramente expresada la posibilidad de quedar ambos paises ligados a beligerantes adversarios entre si. ARCHIVO DEL MINISTERIO DE ASUNTOS EXTERIORES (AMAE). Leg. 1.058. Exp. 8. Nicolás Franco a Conde de Jordana. (Lisboa, 24 de septiembre de 1938.

20 ARQUIVO DO MINISTÉRIO DOS NEGOCIOS ESTRANGEIROS (MNE). P. 2, A. 48, M. 269. Telegrama Ministro dos Negócios Estrangeiros aos ministro e embaixadores. Lisboa, 17 de março de 1939.

21 Enganche propiciado y siempre defendido por Salazar frente a opiniones no siempre coincidentes dentro del aparato diplomático portugues, y que partia del hecho de considerar intimamente unida la estabilidad de su régimen con la situación interna española.

22 Expresadas en el famoso "vencimos, es todo" lanzado por Salazar en un discurso ante la Assembleia Nacional. Heriques, M.C. E Mello, G.: Salazar. Pensamento e doutrina politica. Textos antológicos. Lisboa, Verbo, 1989, pp. 351-352.

23 Unión derivada de la concepción de imperio como compromiso de unidad de los pueblos hispánicos. Ledesma Ramos, Ramiro: Discurso a las juventudes de España. Madrid. La Conquista del Estado, 1935. También para José Antonio la absorción de Portugal era objetivo de esa España rejuvenicida y dinámica que perseguia. Cfr. PAYNE, Stanley: Falange. Historia del fascismo español. Madrid, Sarpe, 1985 , p. 64.

24 Elementos deducibles de la obra más representativa del momento, las Reivindicaciones de España, cuya aparición motivó la intervención del embajador portugués al considerar inaceptables 
que si bien no proclamaba explícitamente la necesidad de una unión ibérica inmediata, sí proponía una progresiva captación que desembocase en la unidad como consecuencia lógica del grado de interrelación que debería unir a ambos países ${ }^{25}$.

El inicio de la II Guerra Mundial hizo que la política española hacia Portugal se viera sumida en una creciente ambigüedad, volviendo ciertamente inestable la base de neutralidad recogida en el Tratado. Si en principio su razón era presionar para impedir que Portugal permitiera la presencia de tropas británicas en su territorio ${ }^{26}$, después de la ocupación alemana de Francia traslucía el giro político español, que preparaba una posible intervención en el conflicto junto a las potencias del Eje ${ }^{27}$. Período de voluntad intervencionista de vigencia limitada, en el que el gobierno franquista se movió con gran prudencia a fin de evitar todos los riesgos posibles para la supervivencia del régimen ${ }^{28}$. Y que en lo referido a Portugal se explicitó en la articulación de una política de captación del país vecino que expulsara la influencia británica de la península, convirtiendo a Lisboa en un centro subordinado de Madrid ${ }^{29}$. Línea que tuvo su expresión más importante con la firma, el 29 de julio de 1940, del I Protocolo Adicional al Tratado de Amistad y No Agresión. Planteada la situación en términos casi tajantes por Serrano ${ }^{30}$, el gobierno luso consiguió en las negociaciones hacer triunfar una vía de equilibrio, intentando evitar

varias afirmaciones alli contenidas y creer necesaria su modificación. AREILzA, J.M. y CASTIELLA, F.M.: Reivindicaciones de España. Madrid, Instituto de Estudios Politicos, 1941. CLNSRF.: Correspondencia...vol. II, p. 324.

25 Vèase, por ejemplo, Cordero TORREs, José Maria: Aspectos de la misión universal de España. Doctrina internacional y colonial de España. Madrid, Vicesecretaría de Educación Popular. 1941. Seminario, Alvaro: España y Portugal: incitaciones a una politica de acercamiento espiritual. Madrid, Espasa-Calpe, 1940.

26. AMAE. Leg. 1081. Exp. 19. Carta reservada Nicolás Franco a ministro Asuntos Exteriores. Lisboa, 1 de septiembre de 1939. Despacho $n^{\circ}$ 87. Nicolás Franco a ministro Asuntos Exteriores. Lisboa, 6 de septiembre de 1939.

27 Marouina, Antonio: España en la política de seguridad occidental, 1939-1986. Madrid, Ejército, 1986, pp. 23-41.

${ }_{28}^{28}$ Prudencia que derivaba de una compleja interrelación de condicionantes internos y externos. Siendo los esenciales la presión en sentido divergente de cada uno de los bloques beligerantes, la nula receptividad alemana a las reivindicaciones territoriales españolas y, sobre todo, la situación de penuria económica que le hacia absolutamente dependientes de unos suministros controlados por Gran Bretaña y que Alemania nunca quiso realizar. Viñas, Angel: Guerra, dinero, dictadura. Ayuda fascista y autarquia en la España de Franco. Barcelona, Critica, 1984.

29 Tusell, J. y Queipo de Llano, G.: Franco y Mussolini. La política española durante la "I Guerra Mundial. Barcelona, Planeta, 1985. P. 88. PAYNE, Stanley: El régimen de Franco. Madrid, Alianza, 1987. p. 285.

30 Según Serrano. Alemania no toleraria un Portugal aliado de Gran Bretaña, por lo que debería abandonar su alianza secular y aproximarse hacia España. Incluso advertía que España, al 
la influencia del cuñado de Franco ${ }^{31}$ y reduciendo su contenido a garantizar simplemente el status quo peninsular ${ }^{32}$. La negativa lusa a abandonar su alianza secular, encauzó las conversaciones en el sentido de una concertación entre sí acerca de los mejores medios para salvaguardar sus intereses mutuos ${ }^{33}$. Fórmula tan elástica que disminuía su importancia real, a pesar de ser suficiente para satisfacer al gobierno español y al portugués, que podria considerarlo un nuevo refuerzo que coadyuvaba a frenar los impulsos intervencionistas españoles ${ }^{34}$.

La tentación intervencionista española continuó hasta la entrevista de Hendaya, en octubre de 1940, de la que salió la firma de un Protocolo de Alianza con el Eje y un compromiso de entrar en la guerra cuando le fueran dados los apoyos económicos y militares necesarios. Aunque España perdió su neutralidad, no existía compromiso militar efectivo y determinado ${ }^{35}$, lo que permitió seguir una política dilatoria que sólo se alteraría si las contrapartidas territoriales fuesen suficientemente satisfactorias y siempre en una fase del conflicto donde la derrota británica fuera inminente. Fase de reflujo nuevamente mal percibida en Lisboa ${ }^{36}$, cuando la hipótesis de intervención española reabrió la vía británica de conversaciones para una colaboración militar en caso de un ataque a Gibraltar ${ }^{37}$. Igualmente, el gobierno luso se sumó a la política británica de presiones moderadas que obligaran a España a no sobrepasar límites tolerables en su no beligerancia bajo el riesgo de un total colapso económico ${ }^{38}$. Política concretada en

estar decidida a solidarizarse con la victoria alemana, se podría ocupar ella misma del asunto si Alemania le requería autorización para el paso de tropas, algo que como "gran potencia", no podria permitir. CLNSRF: Correspondencia... vol. III, pp. 297-323.

31 Maniobra vana pues Serrano conocia detalladamente las negociaciones. TELO, António: Portugal na Segunda Guerra. Lisboa. Perspectiva \& Realidades, 1987, p. 213.

${ }_{32}$ No admitiendo tampoco los matices que Beigbeder quería introducir: que el Protocolo se mantuviera secreto y conllevase la cooperación militar de los dos paises contra una agresión de terceros. DEZ AÑOS... vol II (1971, pp. 247-249).

33 AMAE. Leg. 3372, Exp. 22. I Protocolo Adicional al Tratado de Amistad y No Agresión entre España y Portugal. Lisboa, 29 de julio de 1940.

34 Politica de captación que prosiguió con la sugerencia de realización de reuniones de Estado-Mayor rechazadas por los portugueses. TElo, António: op. cit., p. 213.

35 Marouina, Antonio: op. cit., p. 40.

36 Salazar creia que en esos momentos la decisión de entrar en la guerra ya no dependía de España sino de Alemania. Analizando la hipótesis de que Hitler reclamara a España un ataque a Portugal o el paso de tropas alemanas para ocupar el país. llegaba a la conclusión de que sería muy dificil que el Ejército Español se decidiera a atacar a Portugal, a pesar del estado de ánimo permanente de una parte de la población española acerca del iberismo. Por ello consideraba lo más conveniente proseguir en la línea amistosa seguida hacía España. DEZ AÑOS... vol.VII (1971), pp. $466-467$ y $584-587$.

37 Nogueira, Franco: Salazar III..., p. 320.

38 Morales, Victor: Historia de la no beligerancia española en la II Guerra Mundial. Las 
el acuerdo comercial triangular de 16 de septiembre de 1940, por el cual Portugal facilitaba a España productos coloniales básicos para su economía con cargo al clearing hispano-británico, siendo el año siguiente sustituida la financiación inglesa por créditos portugueses ${ }^{39}$.

Después de desinflarse el ímpetu intervencionista del gobierno franquista, el riesgo de extensión de la guerra a la península se fundamentó en causas exógenas, es decir, en las posibilidades de concreción de una operación alemana sobre Gibraltar, o en una maniobra aliada de anticipación a una eventual acción alemana en la península o de desembarco en las islas atlánticas portuguesas. Situación que paradójicamente no coadyuvó a una mejoría de las relaciones hispano-portuguesas, que se deterioraron gravemente, hasta prácticamente poder hablar de inexistencia de relaciones durante el año $1941^{40}$. Cuando éstas se reanudaron, lo hicieron bajo una atmósfera siempre recelosa que no cambió hasta el cese de Serrano Súñer en septiembre de $1942{ }^{41}$.

\section{LA SUPERACIÓN DEL PELIGRO ESPAÑOL: LA FORMULACIÓN DE LA IDEA DEL BLOQUE IBÉRICO}

El inicio de la campaña alemana contra la Unión Soviética, en junio de 1941, hizo que ambos regímenes coincidieran en señalar que esa campaña descubría la verdadera naturaleza de la guerra, considerando que tras ella Alemania se tornaría en la potencia continental hegemónica ya que Gran Bretaña no podría resistir. Fue, además, el último momento de impulso intervencionista en España, aunque era ya un estímulo muy limitado al coexistir con la intención de no romper la política de apaciguamiento británica. También en Portugal la apertura del frente soviético motivó una revisión de los planteamientos ante la guerra, en el sentido de considerar

Palmas, Mancomunidad de Cabildos de Las Palmas, 1980, p. 117. SMYTH, Denis: Diplomacy and Strategy of Survival: British Policy and Franco's Spain, 1940-41. Cambridge. University Press, 1986.

39 AMAE. Leg. 2.075. Exp. 8. Acuerdo triangular hispano-anglo-portugués. Madrid, 16 de septiembre de 1940. AMAE. Leg. 3243. Exp. 4. Acuerdo económico. Lisboa, 1 de julio de 1941.

40 Claro ejemplo es la campaña antiportuguesa iniciada por la prensa española que culminó con un artículo de Arriba en el que se afirmaba que si cel sentido fraterno no está nutrido de hechos precisos y de realidades comprobadas, lo podemos abandonar por innecesario". Situación encarada por Salazar bajo el presupuesto de no alterar las relaciones con España. ARRIBA, 26 de febrero de 1941. CLNSRF: Correspondencia... vol. II, pp. 196 y 202. Vol. IV, p. 227. DEZ AÑOS... Vol. VIII (1973), pp. 169-179

41 PUBLIC RECORD OFFICE. FOREIGN OFFICE (PRO. FO.). 371/39762. Relations between Spain and Portugal. 5th July 1944. 
que Gran Bretaña deberia pactar al no tener posibilidades de victoria, debiendo aceptar la hegemonía alemana en el continente. Esta visión marcará un cierto giro proalemán en su política ${ }^{42}$, llegando incluso a considerar la posibilidad de enviar una unidad de voluntarios portugueses al frente del Este ${ }^{43}$. Pero, finalmente, la Legiao Portuguesa se limitó a expresar su solidaridad con los que habian marchado a combatir el comunismo considerando más conveniente, al ser la Unión Soviética uno de los aliados de Gran Bretaña, dejar que los españoles monopolizaran la lucha contra el régimen soviético ${ }^{44}$. La prolongación no prevista del frente soviético, que dejaba traslucir una guerra larga de resultado incierto, y la entrada en la guerra de los Estados Unidos alteró nuevamente las perspectivas anteriores, incidiendo en una aproximación entre los dos países, enfrentados ahora al peligro común de la amenaza del comunismo y de su influencia sobre toda Europa, a una reformulación de sus respectivas relaciones con los paises sudamericanos, y al riesgo de una posguerra dominada por principios democráticos que harían difícil la supervivencia de regímenes autoritarios como los ibéricos. Mejoría de relaciones propiciada por el gobierno español intentando utilizar a Portugal ${ }^{45}$, gracias a sus relaciones con Gran Bretaña, para conseguir una mayor aceptación por parte del gobierno norteamericano, en un momento de gravísima crisis económica por la carencia de combustibles ${ }^{46}$.

El primer paso de esta nueva fase fue la entrevista celebrada en febrero de 1942 en Sevilla entre Franco y Salazar, en las que se tocaron varios puntos de interés. Por ejemplo, las presiones alemanas sobre España, que Franco negó existieran en ese momento; la posibilidad, que Salazar descartaba, de un desembarco inglés sobre las islas atlánticas y que Franco dijo considerar como una agresión contra su propio territorio; o la posible articulación de una política común hacia Iberoamérica tendente a

42. Barros, Júlia Leitao de: "Anglofilia e germanofilia em Portugal», en AAVV: Portugal na "I Guerra Mundial. Lisboa, Dom Quixote, 1989, pp. 91-137.

43 RUHL, Klaus-Jörg: Franco, Falange y III Reich. España durante la II Guerra Mundial. Madrid, Akal, 1986, pp. 78-79.

${ }_{44}$ Además, como expresaba el embajador británico en Lisboa, la presencia en el frente de esos sectores más radicales sería una válvula de escape contra los intentos expansionistas más cercanos a casa. PRO. FO. 371/39762. Relations between Spain and Portugal. 5th July, 1944.

45 Teothónio Pereira consideraba que España se encontraba en un momento critico que podria conducirles a aproximarse a Portugal reforzando su neutralidad. CLNSRF: Correspondencia... vol. III, p. 16 .

46 Aproximación diseñada por Franco y Serrano ya que Estados Unidos imponia el fletamento de un petrolero para Portugal. Simultáneamente se hacia el juego con el Eje presentando la aproximación con Portugal como una foma de romper la alianza luso-británica y garantizar la no ocupación de las islas por los aliados. TELo, António: Portugal na Segunda Guerra (1941-1945). 2 vol. Lisboa, Vega, 1991, vol. I, pp. 69-70. 
combatir la penetración de Estados Unidos ${ }^{47}$. Además, Serrano aseguró a Salazar la existencia de maniobras inglesas para derrumbar su régimen, versión que éste rechazó, mostrando no sentir tampoco preocupación del "peligro comunista" interno, aunque sí aceptó acordar una mayor colaboración entre las respectivas policías. Por su parte, Franco garantizó que no iba a reforzar la División Azul y que España sólo entraría en la guerra en caso de un ataque al Marruecos español o de una fuerte presión económica por parte de los aliados ${ }^{48}$.

La entrevista de Sevilla suponía una aproximación política, propiciada por el gobierno franquista y aceptada por Salazar, que contrastaba con el grave contencioso económico existente entre los dos países. Controversia centrada en dos aspectos esenciales. El primero, las importaciones portuguesas de hierro, acero y carbón, de las que España, a pesar de los cupos fijados en el Acuerdo comercial de $1939{ }^{49}$, sólo ofrecía cantidades muy limitadas y a precios exageradamente altos sin respetar tampoco el acuerdo alcanzado de compensación carbón/madera ${ }^{50}$. El segundo, y el más problemático, la contabilización de los tránsitos ferroviarios y el fletamento de petroleros de la CAMPSA para el servicio de Portugal, que España venia prestando desde $1941^{51}$, y que producian un rendimiento en escudos que eran escasamente valorados al preferirse mercancías con las que hacer frente a las necesidades de abastecimiento general ${ }^{52}$. La negociación se prolongó durante todo el año sin conseguir aunar posiciones pues, mientras el gobierno portugués consideraba exagerados los fletes pedidos por España ésta, a su vez no admitía la sobrevaloración que Portugal pretendía de su estaño, argumentando que estos fletes no obtenían reciprocidad, en

47 Según varios autores las conversaciones siguieron las indicaciones trazadas por Von Ribbentrop a Serrano. Es decir, conseguir que Portugal mantuviera su neutralidad resistiendo las presiones angloamericanas, ofreciendo España a cambio la posibilidad de un pacto que garantizara la ayuda española ante tal hipótesis e incluso también la ayuda de Alemania e Italia. Posibilidad de pacto descartada por Salazar que, sin embargo, no tuvo inconveniente en aceptar un acuerdo verbal de consultas reciprocas y de resistencia a intrusiones extranjeras en la península. RuHL, Klaus Jörg: op. cit. p. 80. SuAREZ FERNÁNDEz, Luis: Franco. La Historia y sus documentos. 20 vols. Urbión, 1986, vol. VI, p. 39. SACRISTAN, Ester: "Relaciones peninsulares durante la II Guerra Mundial", en Proserpina, $n^{\circ} 1$ (1984), pp. 145-159.

48 TElo, António: Portugal... vol. Il. pp. 72-73.

49 AMAE. Leg. 1375. Exp. 16. Convenio Económico-mercantil hispano-portugués. Madrid, 12 de diciembre de 1939.

50 CLNSRF: Correspondencia... vol. IV, pp. 30-35; 77-107 y 211-221.

51 Vital para la economia lusa al no existir navios de este tipo en la flota nacional. Rosas, Fernando: Portugal entre a guerra e a paz. Lisboa, Estampa, 1990, pp. 85-86.

52 Divisas que no interesaban en España al ser dificilmente utilizables en la compra de productos portugueses sin poderse tampoco aplicar a la liquidación del clearing comercial. 
atención al extraordinario servicio que prestaban, con facilidades especiales de Portugal en el envio a España de productos de interés ${ }^{53}$. Esta fase de discusión, como también sucediera con el problema anterior, suscitó una fuerte polémica encarada por parte de los dirigentes del Estado Novo a la luz de una concepción permanente subyacente en ellos: la desconfianza y recelo contra la mentalidad española y sus designios contra Portugal ${ }^{54}$. La negociación comenzó a desbloquearse a partir de noviembre, quedando plenamente fijado en el acuerdo comercial de 22 de febrero de 1943 que estipulaba que Portugal compraría a España servicios de tránsito de mercancías y de transportes de petróleos en navíos españoles a precios internacionales. Además, regulaba el intercambio comercial para el año en curso previendo un aumento del $100 \%$ sobre el registrado en el periodo anterior ${ }^{55}$. Previsión excesiva, teniendo en cuenta el efecto de bloqueo que en ese momento ejercía en el intercambio comercial la ausencia de medios de pago por parte española ${ }^{56}$, aunque se alcanzaron cifras que denotaban un moderado refuerzo de las relaciones comerciales entre los dos países, que dejó de ser testimonial para alcanzar un puesto más relevante en el conjunto de los respectivos comercios externos ${ }^{57}$.

El momento más significativo de esta aproximación ibérica vendría en diciembre con el viaje del Conde de Jordana a Lisboa y la proclamación del Bloque Ibérico.

53 AMAE. Leg. 2075. Exp. 15. Portugal. s.f.

54 Salazar hablaba de «bellaqueria, enredo y de la táctica de los grandes señores de España que no hacen ni quieren hacer el menor esfuerzo para darnos hierro y carbón". Argumentos similares utilizaba en Madrid, Theotónio Pereira. DEZ AÑOS... vol. III. (1964), pp. 607-608. CLNSRF: Correspondencia... vol. III. Prólogo, pp. 7-8.

55 MNE. P. 2, A.40, M.173. Carta Theotónio Pereira a presidente do Conselho. Madrid, 22 de tevereiro de 1943. Acordo de Comércio entre Espanha e Portugal, Madrid, 22 de fevereiro de 1943. Diário da Manha, 25 de fevereiro de 1943.

56 MNE. P.2, A.56, M.256. Informaçao da Associaçao de Lisboa sobre a renovaçao do acordo de trocas com a Espanha. Lisboa, fevereiro de 1955.

57 INTERCAMBIO COMERCIAL, 1940-1945 (en miles ptas/oro).

$\begin{array}{rrrrr}\text { AÑO } & \text { IMP. } & \text { EXP. } & \text { SALDO } & \text { TOTAL } \\ 1940 \ldots \ldots \ldots \ldots \ldots \ldots & 13.764 & 2.690 & -11.074 & 16.454 \\ 1941 \ldots \ldots \ldots \ldots \ldots \ldots & 11.285 & 11.051 & -234 & 22.336 \\ 1942 \ldots \ldots \ldots \ldots \ldots \ldots & 24.772 & 7.803 & -16.969 & 32.575 \\ 1943 \ldots \ldots \ldots \ldots \ldots \ldots & 28.946 & 10.546 & -18.400 & 39.492 \\ 1944 \ldots \ldots \ldots \ldots \ldots \ldots & 30.648 & 16.644 & -14.004 & 47.292 \\ 1945 \ldots \ldots \ldots \ldots \ldots \ldots & 31.311 & 20.090 & -11.221 & 5.401\end{array}$

FUENTE: Ruiz Morales, J. M.: La economia del bloque hispano-portugués. Madrid, Instituto Estudios Politicos, 1946, p. 346. 
La idea del Bloque Ibérico debemos encuadrarla dentro de las distintas iniciativas ante la guerra lanzadas por ambos regímenes, en busca de una nueva situación de equilibrio europeo asumible desde su peculiar concepción político-ideológica. Propuestas coincidentes en dos momentos básicos: uno, hasta 1940, en el que ambos afirman la inoportunidad de la guerra y la necesidad de llegar a acuerdos realistas que tuvieran en cuenta las reivindicaciones italo-alemanas; otro, después de la entrada en la guerra de la Unión Soviética y Estados Unidos, lanzando la idea de una paz de compromiso sin vencedores ni vencidos, que preservase una Alemania fuerte capaz de contener la amenaza soviética ${ }^{58}$. Acuerdo de objetivos que no condujo a una estrategia de actuación conjunta salvo en 1942 , cuando ambas diplomacias se coordinaron ${ }^{59}$ para conseguir articular esa zona iberoamericana de paz perseguida por Salazar desde, prácticamente, el inicio del conflicto. Las resoluciones de la Conferencia Pan-americana de Río de Janeiro y la declaración formal de guerra al Eje de la casi totalidad de Estados Iberoamericanos, salvo Argentina y Chile, marcaron, evidentemente, el fracaso de estas iniciativas y su encauzamiento hacia fórmulas más sencillas como era la del Bloque lbérico.

Después de abandonar las propuestas de paz de alcance más general, encaminadas a garantizar la permanencia y asentamiento de unos regímenes con las que ambas dictaduras ibéricas se sentian solidarios, franquismo y salazarismo retomaron iniciativas más limitadas que desembocaron, en diciembre de 1942, en la proclamación del Bloque Ibérico. Era ya una expresión diferente de las anteriores en cuanto el decidido giro proaliado que la guerra había adquirido desde el otoño, exigía una coordinación más atenta a su propia supervivencia que intentos de mediación de corte claramente pro-Eje. Por tanto, la formación del Bloque lbérico suponía una postura claramente defensiva y fuertemente represiva de cara a los nuevos vientos que soplarian de una Europa políticamente dividida entre las revitalizadas ideas democráticas y las nuevas ideas inspiradas

58 Manuel Loff propone el concepto de appeasement aplicado a los objetivos de la política exterior portuguesa y española en los años 1936-1941 y 1943-1945 como un concepto operativo para la reinterpretación del pensamiento internacional de ambos regimenes. Loff, Manuel: Franquismo y Salazarismo en la época de Hitler. Régimen político, prejuicio ideológico y oportunidad histórica en la redefinición internacional de Portugal y España (1936-1942). Memoria de Licenciatura presentada en la UNED, Madrid, 1993, p. 162 y 164.

59 Idea que presentaba dos aspectos esenciales: ser considerada favorable al Eje e intentar romper la influencia de Estados Unidos sobre la zona y que se saldó, tanto para España como para Portugal de forma muy negativa en sus respectivas relaciones con las republicas hispanoamericanas y con Brasil. Loff, Manuel: Franquismo y Salazarismo..., pp. 170 y ss. Telo, António: Portugal... vol. I, pp. 79 y ss. 
por la Unión Soviética ${ }^{60}$. Asi lo expresaban las conversaciones mantenidas por el Conde de Jordana durante su estancia en Lisboa que giraron, fundamentalmente, en torno a una posible postura común de ambos países frente a la amenaza comunista, para ellos, el verdadero problema que escondía la rivalidad germano-británica y el auténtico enemigo que amenazaba destruir la civilización cristiana occidental. Tanto Jordana como Salazar estaban de acuerdo en considerar que un triunfo absoluto de Gran Bretaña supondría la expansión del Ejército Rojo por todo el continente, que se veria sacudido por fuertes convulsiones revolucionarias. Por eso, proclamándose verdaderos defensores de esta civilización, aceptaban constituir un sólido bloque que actuara como barrera frente a la expansión comunista ${ }^{61}$.

Para el gobierno español la intención más evidente era utilizar la vinculación portuguesa con ánimo propagandistico, para resaltar que su mantenimiento al margen de la guerra respondía a una orientación política permanente, intentando un cierto desmarque en un momento donde los aliados empezaban a alcanzar posiciones de ventaja en el transcurso del conflicto bélico ${ }^{62}$. También dejaba traslucir los principales elementos que utilizará el franquismo para preparar su acomodación a la nueva realidad de posguerra: remarcar cómo el régimen español respondia, como el portugués, a una solución propia sin vinculaciones con fórmulas exteriores; la consideración de su particular esencia católica; y, finalmente su profesión anticomunista extrema ${ }^{63}$. Esta posición defensiva frente a un contexto externo potencialmente hostil, coincidia básicamente con la postura asumida por el salazarismo pero, sobre todo, respondía a la convicción salazarista de que su propia estabilidad estaba fuertemente ligada a la situación interna española. En otro sentido, era la culminación de la política diseñada desde el inicio de la conflagración; es decir, atraer a España a un pacto tácito que uniera a los dos países sin necesidad de compromisos rígidos, además de ser una solución muy aceptable al problema de las relaciones con España. Al mismo tiempo, una plataforma conjunta alejaría el

60 Rosas, Fernando: Portugal... p. 76.

61 Además, Jordana garantizó que la Ley de movilización española de 16 de noviembre no iba dirigida contra Portugal y explicó la concepción española de no beligerancia como la voluntad decidida de no entrar en la guerra, aunque el efecto distorsionador del comunismo no le permitiera tener una postura totalmente imparcial ante los dos bandos. AMAE. Leg. 1375. Exp. 16. Borrador de temas de conversación del Sr. ministro de Asuntos Exteriores con el presidente de la República portuguesa y con el Dr. Oliveira Salazar. 16 de diciembre de 1942.

62 Doussinague, José $M^{a}$ : España tenía razón. Madrid, Espasa-Calpe, 1949, p. 118.

6.3 DOCUMENTOS SOBRE EL BLOQUE IBERICO. Madrid, MAE, 1942. 
riesgo de intervención alemana o de desembarco aliado en la Península, reforzando el compromiso del gobierno franquista con la no beligerancia. Finalmente, se pensaba que la conjunción de las dos dictaduras actuando internacionalmente de forma solidaria conferiria mayor fuerza a unos regimenes de difícil acomodación en una sociedad postbélica como la que se comenzaba a dibujar. Por tanto, estaban perfectamente de acuerdo en suscribir la fórmula de una península unida en su acción exterior, aunque para ello era necesario explicitar la rotunda e irreversible separación política de los dos Estados para no incitar un iberismo que se creía siempre latente en el espíritu español ${ }^{64}$.

En este nuevo contexto de solidaridad ibérica. Portugal pudo hacer frente sin tantos temores a las crecientes presiones anglo-americanas sobre la utilización militar de las Islas Açores. En el marco de las negociaciones, Gran Bretaña aceptó preparar un nuevo plan de defensa que, dada la insistencia portuguesa, comprendiese la posibilidad de un ataque español, aunque siempre dejó clara que su intención era sólo preparar los planes y nunca ejecutarlos ${ }^{65}$. Garantías, en todo caso, ya innecesarias por cuanto el ministro Jordana, en una nueva entrevista con Salazar celebrada en Ciudad Rodrigo, expresó su comprensión por la postura del gobierno portugués y el decidido apoyo español, dando todas las seguridades en cuanto al mantenimiento de la neutralidad española ${ }^{66}$.

La proclamación del Bloque Ibérico supone un momento de inflexión histórica determinante en el transcurso de las relaciones entre los dos países peninsulares. Corte producto, en gran parte, de la casi desaparición como elemento político operativo del factor histórico esencial de antagonismo: el iberismo. Al mismo tiempo, la percepción portuguesa de peligro español disminuyó notablemente en cuanto a amenaza directa, aunque no desapareció por completo. De esta forma, el lanzamiento de la idea del Bloque Ibérico va a suponer un momento de transición estructural fundamental, de permanencia y evolución, que irá conformando una nueva realidad peninsular, aunque siempre en un discurrir lento y con evidentes dificultades de encauzamiento.

\footnotetext{
64 Por ello utilizaban la fórmula de Bloque Peninsular para evitar cuatquier posible confusión. PORTUGAL, Boletim do SNI. Lisboa, Dezembro de 1942, p. 5.

65 Según Marquina, la oferta británica ofrecia una ayuda no planteada en términos generales sino una defensa efectiva contra un ataque incluso si procedia de España. MaRQuiNA, Antonio: $o p$. cit., p. 94.

66 Nogueira, Franco: Salazar III..., p. 470. Castro, Augusto de: Subsidios para a história da política externa portuguesa durante a guerra. Lisboa, Livraria Bertrand, 1958. MARQuina, Antonio: op. cit., p. 96.
} 
Se inicia desde entonces una fase en la que el estímulo de antagonismo representado por el iberismo va dejando de ser determinante político básico en el modo de relación de los dos países, siendo sustituido como tal por diferentes problemas más acordes con las nuevas características de una sociedad internacional en formación y crecientemente interrelacionada e interdependiente, y la nueva ubicación de una sociedad así exigía a los dos regímenes dictatoriales ${ }^{67}$. Pero es una evolución no acabada, indisociable del concepto de permanencia, por cuanto la prevención portuguesa frente a España seguirá presente tamizando ciertas posibilidades de un mayor estrechamiento peninsular, aunque sin esa connotación determinante propia de situaciones anteriores ${ }^{68}$. Inscrita en este binomio en cierto sentido contradictorio, la relación peninsular se impregnará de esta característica, oscilando entre la intimidad y el alejamiento, en una continua expresión de posibilidades abortadas, de intentos fracasados de articular una relación llena de contenido.

La evolución señalada en la relación peninsular parte de un significativo cambio en los presupuestos teóricos hacia el país vecino que la idea del Bloque Ibérico llevaba aparejada. Alteración de planteamientos no circunscrita únicamente al ámbito peninsular, sino que reflejaba una inflexión de alcance más amplio en el pensamiento político prevalente en el régimen franquista ya que, es en estos momentos, cuando los círculos de ubicación más estrictamente conservadora y tradicionalista inician una reacción frente a la preminencia que hasta entonces había ocupado el pensamiento falangista ${ }^{69}$. Este grupo, que comienza por atribuirse la dirección espiritual del Alzamiento de 1936, postulaba un retorno a las ideas patrióticas y religiosas de una línea política y cultural que comenzaba en Menéndez Pelayo, seguía con Vázquez de Mella y finalizaba en Ramiro de Maeztu y el grupo de Acción Española ${ }^{70}$. Una doctrina, caracterizada por un retorno a los valores antirrevolucionarios y a las tradiciones católicas y nacionales, de difícil conjugación con la ortodoxia falangista. Inadecuación doctrinal que dejaba traslucir, en el fondo, un enfrentamiento entre esa

67 JimÉnez Redondo, Juan Carlos: Franco e Salazar. As relaçoes luso-espanhoanl no contexto da guerra fría. Lisboa, Assirio \& Alvim, (inminente publicación).

${ }_{68}$ Sintomática de esta pervivencia es la negativa reacción portuguesa hacia la política de la Hispanidad. Expresión de un nuevo iberismo en su prolongación iberoamericana, revierte en un claro factor de bloqueo para un entendimiento más confiado. JIMÉNEZ REDONDO, Juan Carlos: “La pervivencia del recelo antiespañol: la reacción portuguesa a la política española hacia Iberoamérica", en TORRE, Hipólito de la (Coord.): Portugal, España y América. Pasado y Presente de un proyecto. Siglos XIX y XX. Mérida, UNED, 1993, pp. 255-278

69 Diaz, Elias: Pensamiento español en la era de Franco (1939-1975). Madrid, Tecnos, 1992, p. 32 .

to Ibidem. P. 33. 
vieja extrema derecha tradicionalista y la nueva derecha asociada al falangismo, con más propensión al totalitarismo fascista ${ }^{71}$.

Esta alternancia de primacía ideológica dentro del régimen español tuvo sus ejemplos más llamativos en el cambio de los planteamientos teóricos hacia Hispanoamérica y hacia Portugal, vértices de la política exterior en muchos casos asociados y de evolución paralela. En el caso del hispanoamericanismo, es en esa fecha cuando se abandona el ideal que llevaba implícito la creación del Consejo de la Hispanidad ${ }^{72}$, que nacía como expresión de la ideología fascista de Falange que enlazaba con la idea de Imperio: Hispanoamérica como área de influencia preferencial de España sin descartarse una eventual unificación futura, intentando restaurar la conciencia unitaria del mundo hispánico ${ }^{73}$. Desde 1942, a partir de la revisión de la política española hacia planteamientos menos comprometidos, se retomó la visión católico-integrista de la Hispanidad, asentada sobre la comunidad espiritual y los vínculos culturales ${ }^{74}$, olvidándose las anteriores veleidades de prepotencia moral, ideológica e incluso política. En definitiva, encaminada a configurar la Hispanidad como una doctrina de unidad cultural y espiritual que transcendía cualquier realización politica.

Evolución paralela siguen los postulados teóricos hacia el país vecino, retomándose los presupuestos ententistas y arrinconado progresivamente las anteriores propuestas pseudoiberizantes y paternalistas. Inflexión que ya se había producido en el pensamiento de la derecha española ${ }^{75}$, aunque en fase germinal, durante la monarquia alfonsina, que había comenzado a aparcar las tesis unionistas de un Vázquez de Mella ${ }^{76}$, en beneficio de una nueva expresión aliancista superadora y niveladora de la relación peninsular. Durante la Dictadura del general Primo de Rivera acabó de perfilarse esta evolución, no quedando reducida sólo a meras formulaciones teóricas sino trasladada a la acción política, aunque no fue

71 Ibidem, pp. 36-37

72 Barbeito Diez, Mercedes: "El Consejo de la Hispanidad", en Espacio, Tiempo y Forma. Historia Contemporánea. Serie V (1989). pp. 113-141.

73 AREnAl, Celestino del: España e Iberoamérica. De la Hispanidad a la Comunidad Iberoamericana de Naciones. Madrid, CEDEAL, 1989.

74 DELGADO, Lorenzo: Diplomacia franquista y politica cultural hacia lberoamérica. Madrid, CSIC, 1988, p. 81 .

75 TORRE, Hipólito: "Una obra clave numa historiografia em ascensao". Prefacio a JIMÉNEZ REDondo, Juan Carlos: op. cit.

76 Defensor de una federación con Portugal en la forma de una monarquia dual o de imperio, con una monarquia subordinada en lo internacional. VAZQUEz dE MELLA, Juan: Obras Completas. Vol. II. Madrid. 1960. 
hasta el segundo bienio republicano cuando surgió verdaderamente la posibilidad de hacer realidad un tratado político entre ambos Estados ${ }^{77}$.

El franquismo retomará a partir de 1942 esta línea aliancista sustentada en la realidad del Tratado de Amistad y No Agresión de 1939 y en el posterior Protocolo Adicional. Desposeídos de la carga iberizante con la que nacieron, aparecen ahora como marco juridico estable que fundamentaba la idea del Bloque Ibérico, permitiendo hacer reposar en ellos toda la retórica inherente al mismo. Retomando la linea marcada por el escritor portugués António Sardinha, asimilada por completo por el grupo de Acción Española, suponía, esencialmente, el respeto a la integridad nacional del pais vecino considerando irreversible la separación política de la península. Esta división política pasaba a ser considerada secundaria ya que se reputaba que la península formaba una unidad espiritual, que trascendia aquella, conforme a una fundamentación común basada en la civilización cristiana occidental, de la que ambos paises se declaraban sus verdaderos depositarios, y un compartido destino histórico. Máximo representante del Integralismo Lusitano ${ }^{78}$, Sardinha planteaba en su obra una nueva propuesta, nacionalista y reaccionaria, para la regeneración integral del país ${ }^{79}$. Si en el orden interno la solución era la monarquía tradicional y el régimen antidemocrático y antiparlamentario, dentro de un Estado fuertemente centralizado y organizado bajo principios corporativos; en el plano internacional proponía la vinculación con España como único camino para establecer una plataforma fuerte que asegurara la proyección exterior del país, garantizara su viabilidad como Estado independiente y robusteciera la fuerza nacional portuguesa. Alianza, en fin, que preservando la inquebrantable independencia política de ambos Estados, se proyectase, con su marcado destino imperial, hacia América. Remitiendo a esta especie de supranacionalismo ibérico, este concepto de alianza enlazaba con el de la Hispanidad dibujado por Ramiro de Maeztu ${ }^{80}$ : una unión espiritual y cultural basada en la historia paralela y en su vínculo común de naciones cristianas. Concepción del imperio que, siguiendo al Marqués de Quintanar, carecia de connotaciones beligerantes o peligrosas con respecto a otras naciones, ya que se limitaba a la plasmación de un ideario y una tarea: la de salvar la concepción espiritual y religiosa de la civilización cristiana, tarea que

\footnotetext{
77 Posibilidad estudiada en 1935. MNE. P.2, A.49, M.123. Of. 103. Embaixada de Portugal em Londres a ministro dos Negócios Estrangeiros. Londres, 5 de Julho de 1935

78 CRuz, Manuel Braga da: "O Integralismo Lusitano e o Estado Novo", en AAVV: O fascismo em Portugal. Lisboa, Regras do Jogo, 1982.

79 Sardinha, António: La Alianza Peninsular. Madrid, Imp. Sáez Hermanos, 1930.

so Maeztu, Ramiro de: Defensa de la Hispanidad Valladolid. Aldos, 1938.
} 
España debía compartir con Portugal, eje como ella de esa civilización cristiana occidental ${ }^{81}$.

Como ya hemos señalado, la obra de Sardinha encontró en España calurosa acogida, convirtiéndose en el modelo ideológico asumido por el grupo de Acción Española y, posteriormente, por el franquismo ${ }^{82}$, siendo decisiva para comprender toda la retórica surgida a partir de 1942. En cambio, en su pais fue mucho menos aceptada y, aunque también contribuyó a diseñar una nueva visión del problema español desde una perspectiva de complementaridad y no de enfrentamiento ${ }^{83}$, no sirvió de exclusivo marco de referencia a la hora de abordar la problemática derivada del contencioso peninsular.

La proclamación del Bloque lbérico no fue, sin embargo, acompañada de una inmediata intensificación de las relaciones entre ambos regímenes. Al contrario, ambos gobiernos fueron incapaces de articular una respuesta coordinada frente a la nueva situación de la guerra, ya que ninguno de ellos intento dotar de contenido o atender las posibilidades que, más allá de la mera retórica propagandística, abría el Bloque Ibérico ${ }^{84}$. Prueba de esta ineficacia fue la incapacidad de sostener incluso mera consultas cuando, a principio de 1943, el gobierno franquista lanzó su propuesta mediadora para una paz de compromiso. Incluidos en la propuesta sin previo asentimiento, la reacción portuguesa fue sustancialmente significativa, tachándolas Theotónio Pereira de absurdas y parciales, refiriéndose a Franco con duras palabras: «Este sujeto continua a ver poco claro y todas sus ideas e iniciativas en el campo internacional me parecen tocadas de infelicidad" ${ }^{35}$. Pero la ausencia de contenido del Bloque Ibérico se puede rastrear en otros aspectos fundamentales que ambos gobiernos encararon por separado, sin ningún tipo de consultas mutuas o cambio de información. Asi sucedió en el inicio de las negociaciones sobre el wolframio; en las negociaciones llevadas a cabo por Portugal para la cesión de facilidades para el uso militar de

\footnotetext{
81 Quintanar, Marqués de: Diálogo peninsular. Madrid. Ediciones de Cultura Hispánica, 1977, p. 56 .

82 Confirmando en este punto ese "continuum" que existe entre el general Primo de Rivera y el general Franco, enlace entre una vieja/nueva doctrina político-social realizado a través del grupo de Acción Española y que, en definitiva, asentará, con tensiones claras con los grupos católicos y con los nuevos nacionalistas modernistas, las bases reales del Estado franquista. Morodo, Raúl: Los origenes ideológicos del franquismo. Acción Española. Madrid, Alianza, 1985.

83 Véase como ejemplo Mendes CoRAEA, A.A.: O Bloco peninsular. Lisboa, Ocidente, 1943.

${ }^{84}$ Ineficacia que el embajador portugués en Madrid atribuia a los sectores falangistas del gobierno español, representados por Arrese, y al propio Franco. CLNSRF: Correspondencia... Vol. IV, p. 45.
}

85 Ibidem, pp. 188; 114, 119 y 144 
las Islas Açores que, incluso fueron deliberadamente ocultadas por el gobierno luso hasta el último momento; o las negociaciones de España con Estados Unidos sobre la utilización de aeropuertos españoles. Únicamente un aspecto merece ser resaltado como exponente de una colaboración eficaz más discontinua: la coordinación de las respectivas polícias frente a posibles amenazas subversivas. Colaboración que partía de los inicios de la Guerra Civil, siendo su ejemplo más característico la ayuda prestada por el gobierno portugués en la toma de Badajoz ${ }^{86}$, y que se mantuvo siempre que las circunstancias amenazaron favorecer sacudidas revolucionarias. Pero, incluso en este terreno, asistimos a esa discontinuidad aludida, como demuestran las facilidades concedidas por el gobierno portugués a la evacuación desde su territorio de varios miles de refugiados españoles de la guerra civil con destino a Francia y Sudamérica ${ }^{87}$.

\section{España y Portugal ante el fin de la guerra}

El desarrollo cambiante de las relaciones peninsulares durante el conflicto bélico alcanzó un nuevo punto de inflexión a partir de finales de 1943 y principios del año siguiente, teniendo como telón de fondo la defensa de las dictaduras en un contexto externo incierto. Aunque la seguridad de una derrota definitiva del Eje hizo evolucionar rápidamente la posición española, la disponibilidad mostrada hacia el bando vencido repercutió en una creciente hostilidad por parte de los aliados con respecto al régimen franquista, considerando un residuo fascista al que era necesario barrer. Dificultades que el salazarismo nunca encontró al mantener en principio una posición más equidistante entre los bandos beligerantes y más tarde

86 Burgos Madronero, Manuel: "A fiscalizaçao das fronteiras portuguesas durante a Guerra Civil da Espanha", en AAVV: O Estado Novo. Das origens ao fim da autarçia. 2 vols. Lisboa, Fragmentos, 1987, vol. I, pp. 367-369. REIG TAPIA, Alberto: La represión franquista y la Guerra Civil. Consideraciones metodológicas, instrumentalización política y justificación ideológica. 2 vols. Madrid, UCM, 1983, vol. II, pp. 742-774. Neves, Mário: A cacinha de Badajoz. Lisboa, O Jornal, 1985.

87 El gobierno luso, de acuerdo con el ministro de México en Lisboa, que era quien posibilitaba la permanencia clandestina de españoles en Portugal, facilitaba su salidad apoyándose en una organización denominada Unitarian Service Comitte. A pesar de las quejas españolas, Salazar prolongó sus actividades hasta febrero de 1949 cuando acabó con sus actividades, siendo los exilados internados en la fortaleza de Peniche. MNE. P.2, A.50, M.42. Telegrama Legaçao Portugal em México a ministro dos Negócios Estrangeiros. México, 16 de decembro de 1945. Telegrama Ministro dos Negócios Estrangeiros para Legaçao de Portugal em México. Lisboa, 25 de decembro de 1945. Of. 439. Dtor. dos Negócios Politicos a Dtor PVDE. Lisboa, 20 novembro de 1945. AMAE. Leg. 3374. Exp. 12. Despacho 293. Embajador a ministro Asuntos Exteriores. Lisboa, 13 de abril de 1949 . 
claramente proaliada, concediendo incluso facilidades para la utilización de las islas Açores, y tener un origen oscuro y lejano muy diferente de una guerra civil tan traumática y emblemática como la española. Sin embargo, a pesar de tener conciencia de estar mejor situados de cara a la posguerra que el gobierno franquista, no dejaron de estar presentes ciertas dudas y reticencias, lo que empujó a Salazar a evitar que Franco sucumbiera a la victoria aliada, ya que él mismo podría verse arrastrado en la caída. Por tanto, asumiendo la convicción de que su régimen estaba muy ligado a la paz interna de España ${ }^{88}$, Salazar asumió nuevamente el papel de interlocutor internacional del franquismo, intentando presentar una península unida en actitudes y deseos políticos en armonía con la posición de los países anglosajones, utilizando propagandisticamente, como se hará en España, el Bloque Ibérico como soporte básico de la neutralidad peninsular ${ }^{89}$. Incluso llegó a renunciar a la firma de un ventajoso acuerdo con los aliados sobre las exportaciones de wolframio a Alemania, que propició un momento de gravísima crisis debido al embargo de abastecimientos utilizado por los anglosajones en la negociación, para apoyar al gobierno español en las negociaciones que éste mantenía con Gran Bretaña y Estados Unidos. Prueba evidente de la importancia que Salazar concedía a España en el marco general de la política externa portuguesa ${ }^{90}$.

El fin de la guerra en Europa acentuó el proceso de aislamiento internacional del franquismo, recibiendo la primera condena en junio a consecuencia de la moción presentada por el delegado mexicano durante la tercera sesión de la 1 Comisión de la Conferencia de las Naciones Unidas, inaugurada el 25 de marzo en San Francisco. En ella, sin citar a España, se le negaba la posibilidad de ingresar en la organización al ser un régimen establecido con la ayuda de los países del Eje. Proscripción conformada posteriormente en la Declaración final de la Conferencia de Potsdam ${ }^{91}$.

Siguiendo una estrategia de enganche, el gobierno español pretendió utilizar la via portuguesa como conexión con Gran Bretaña, intentando conformar un frente solidario que le permitiera afrontar estas dificultades con la garantía de estabilidad y homogeneidad política de la peninsula ${ }^{92}$.

88 CLNSRF: Correspondencia... vol. IV, p. 734

89 Diário de Noticias, 16 de junho de 1944, 24 de abril de 1945. Diário de Manha, 22 de janeiro de 1945. SALAZAR, António de Oliveira: Portugal y la Paz. Lisboa, SNI, 1945, pp. 13-28.

90 Telo, António: Portugal... vol. I, pp. 223-239.

9 Lleonart, A.J. y Castiela, F.M.: España y ONU. I (1945-1946). Madrid, CSIC, 1978. Portero, Florentino: Franco aislado. La cuestión española. Madrid, Aguilar/Maior, 1989.

92 MNE. P.2, A.49, M.123. Apontamento de conversa como o embaixador de Espanha, 6 de agosto de 1945. 
La intención del gobierno español era, en una fijación de objetivos bastante poco realista, que fueran los portugueses quienes abrieran la via de diálogo con Gran Bretaña que, a su vez, permitiria una mejor relación con Francia y una aproximación mediterránea hispano-anglo-italiana, además de actuar como soporte imprescindible para afrontar desde posiciones de orden posibles sacudidas revolucionarias ${ }^{93}$.

El gobierno portugués analizó la cuestión introduciendo algunos factores de prevención, ya presentes desde la Declaración de Potsdam. Para Salazar era fundamental dilucidar si el comunicado final de la conferencia era una satisfacción dada a la opinión pública de algunos países o era el punto de partida de futuros ataques encaminados a minar al régimen español hasta conseguir su sustitución. A su juicio, era claramente un tributo dado a la URSS, al laborismo británico y a una parte importante de la opinión pública norteamericana, considerando que la evolución de los acontecimientos sería en un sentido favorable ya que, en la situación ruinosa de Europa, los intereses británicos y americanos primarian al ser los dos países peninsulares "los únicos apoyos" todavia "seguros" como representantes "de un ideal de orden, trabajo, jerarquia y autoridad". En consecuencia, si no había intención de hacer caer al régimen español, la posición portuguesa sería la de trabajar para crear circunstancias favorables para un entendimiento futuro. Pero si no era así, consideraba más conveniente declararse no solidario con el gobierno franquista, estimando que no les afectaba un cambio de régimen en España, siempre y cuando no supusiera la vuelta de los republicanos, ya que con éstos en el poder la estabilidad interna de Portugal seria imposible ${ }^{94}$. Si la permanencia del general Franco no fuese posible, la solución más factible sería una restauración monárquica fuertemente controlada y tutelada por el Ejército como garantía de estabilidad ${ }^{95}$. Por eso fueron siempre partidarios de un entendimiento directo entre Franco y D. Juan, como única fórmula que a medio o largo plazo solucionase el problema español sobre bases lo suficientemente estables como para no ver comprometida la tranquilidad de su propio pais. Sin embargo, la política de ruptura llevada a cabo por $\mathrm{D}$. Juan, que consideraban

\footnotetext{
93 AMAE. Leg. 1374. Exp. 10. Instrucciones para el embajador de España en Londres al iniciar su ernbajada. 1 de diciembre de 1946. Carta ministro Asuntos Exteriores a embajador en Londres. Madrid, 3 de diciembre de 1945. AMAE. Leg. 1374. Exp. 2. Instrucciones para el embajador de España en Roma. Madrid, 7 de enero de 1946.

94 MNE. P.2, A.48, M.178. Telegrama ministro dos Negócios Estrangeiros ás embaixadas de Londres e Washington. 10 de agosto de 1945.

95 PRO. FO. 371/60446. No 67. M55/189/46. British Embassy. O'Malley to Mr. Bevin. Lisbon, March 7th, 1946.
} 
arruinaba todas las posibilidades de restauración, les hizo convencerse de la imposibilidad de llegar a una solución práctica en este terreno, confirmando su preferencia por el mantenimiento de Franco en el poder ya que pensaban que la alternativa a su caida sólo podría ser la vuelta de los republicanos exilados y, en definitiva, el reinicio de la contienda civil ${ }^{96}$.

La progresiva gravedad que iba adquiriendo la cuestión española aconsejó al régimen salazarista abandonar su anterior línea de apoyo público e incondicional para evitar verse «salpicado» por este problema. Evolución hacia un mayor distanciamiento evitando que el nombre de los dos países apareciera unido o pudieran darse identificaciones peligrosas ente ellos ${ }^{97}$. Pero no conviene exagerar su alcance. Aunque parece claro que este despegue existió desde el otoño de 1945, llegando hasta mediados de 1947, no supuso un abandono total de la actitud favorable hacia el régimen español, ya que nunca dejo de apoyar, sobre todo ante Gran Bretaña ${ }^{98}$, una solución exclusivamente interna al problema español lo que, en definitiva, siempre favorecia la permanencia del general Franco en el poder al no admitir presiones externas para conseguir la evolución del régimen.

\section{CONCLUSIÓN}

El período de la II Guerra Mundial supuso una resurrección del inveterado peligro español no sólo por el predominio de Falange, sino también por su vinculación enfeudada respecto a las potencias del Eje y por la idea de que la intervención de cualquiera de los dos Estados arrastraría irremediablemente a toda la península al conflicto. Sin embargo, el giro dado por el gobierno español a partir de 1942 hacia posiciones más moderadas permitió superar, hasta donde era estructuralmente posible, estas circunstancias. Para el gobierno salazarista el Bloque Ibérico constituía un éxito constatable de la nueva política ibérica iniciada en 1936, pues se aseguraba una España sin intenciones agresivas tanto por la nueva orientación del gobierno español, permanente ya durante todo el período de la dictadura,

\footnotetext{
96 MNE. P. 2, A. 47, M. 129. Telegrama ministro dos Negocios Estrangeiros para Londres e Washington. Lisboa, 2 de março de 1946. PRO. FO. 371/60446. Minutes, 2 may, 1946.

97 AMAE. Leg. 2301. Exp. 2. Despacho 512. Embajador a ministro Asuntos Exteriores. Lisboa, 13 de octubre de 1945. AMAE. Leg. 1705. Exp. 7. Informe 170-E. Agregado de Prensa a vicesecretario Educación Popular, 2 de octubre de 1945.

98 El Foreign Office se planteó la posibilidad de implicar a Salazar en su política hacia España para persuadir a Franco de su marcha del poder. Pero finalmente se desistió no creer deseable que Gran Bretaña discutiera su politica hacia España con Salazar. PRO. FO. 371/60446. Foreign Office to ambassador in Lisbon. London. March, 1946. Minutes. Ist, March, 1946.
} 
como por la propia impotencia internacional de éste en el nuevo contexto internacional. Además de superar airosamente la problemática propiciada por España, Salazar había conseguido acrecentar el prestigio internacional del país, con una política autónoma y no estrictamente dependiente de la británica, y asentar su propia dictadura sobre bases más sólidas que las existentes diez años atrás. Sin embargo, su propia línea hacia España le enganchó con un régimen no aceptado internacionalmente, desprendiéndose comparaciones siempre peligrosas para su propia supervivencia, además de condicionarle negativamente en aspectos básicos, como el wolframio, en los que podia haber sacado mayor provecho si hubiera renunciado a su política de alineamiento con el régimen franquista. Finalmente, evaluó mal la nueva realidad impuesta por la guerra, anclado en un fuerte antiamericanismo y pretendiendo vincularse con una Gran Bretaña que ya había perdido el papel de potencia mundial anterior. Línea que tenía una explicación clara: el mantenimiento de las colonias en un mundo donde las proclamas anticoloniales estaban ya en primer plano. Todo ello redundó en una acomodación difícil y problemática, llena de dudas, a la posguerra.

El gobierno franquista explotó la conexión portuguesa sin preocuparse de dotar, igual que el salazarista, de mayor contenido las relaciones peninsulares. Con ello, las posibilidades de una estrategia común ibérica de acomodación a la victoria aliada se revelaron escasas, a pesar de que ambas dictaduras utilizaron los mismos argumentos teóricos para conseguirlo: su componente católico y anticomunista, su neutralidad o no beligerancia en la guerra, y su independencia de régimen político con respecto a las fórmulas vencidas en la guerra.

En cuanto al papel de Portugal en el mantenimiento de la neuiralidad española, éste no fue tan decisivo ni determinante como los dirigentes del Estado Novo se atribuian, ya que fue causa de una interrelación compleja de factores que escapaban de las posibilidades de actuación del gobierno portugués. Con todo, debemos admitir un apreciable efecto de freno a la hora de una acción más decidida. Enfrentado a la posibilidad de una inmediata respuesta británica en las costas lusas, Franco se decantó por seguir una cautelosa política de atracción del país vecino que le apartase de Gran Bretaña. Más decisiva fue la postura portuguesa vista en otro sentido. La política salazarista de neutralización de la península sí jugó un papel esencial para impedir la extensión del conflicto más allá de los Pirineos al frenar posiciones más definitivas tanto por parte de España como, especialmente, de Gran Bretaña, cuya estrategia hubiera tenido que ser distinta en el caso de una Península Ibérica volcada no sólo ideológica, sino militarmente, hacia el Eje. 
Sin considerar los aspectos estrictamente dependientes de la intervención en la guerra, la última conclusión importante que podemos resaltar es como ambos regímenes buscaron desde 1942 una vía de acomodación a un contexto internacional que desde ese momento parecía dominado por dos ideas expansivas, comunismo y democracia parlamentaria, que ambos regímenes rechazaban de acuerdo a su propia definición ideológica. Intentos que traslucian el evidente anhelo de ambas dictaduras en asegurar su supervivencia y sus deseos de perdurar en el tiempo. Para ello, ambas aceptaron ciertas concesiones formales que no afectaban en absoluto a su naturaleza dictatorial. Adaptación a una determinada situación internacional que ya se había producido, en sentido contrario, en el periodo 1936-1942 animada no sólo por un mero afán de supervivencia sino por una afinidad ideológica concreta. Ambos regímenes, aunque el caso español sea más explícito, buscaron de forma consciente acomodarse dentro del nuevo Orden Europeo que las potencias fascistas parecian en disposición de inaugurar. Y, para ello, no sólo adoptaron unos planteamientos internacionales complacientes, y en casos solidarios, con el revisionismo italo-alemán, sino una política interna adaptada en lo fundamental a estos principios. 